\title{
D-STATCOM Optimal Placement and Sizing in the Distribution System with JCF-LA Approach
}

\author{
Dr. Vishwanath Patil \\ Borregaard, Oslo, Norway \\ vispat96@gmail.com
}

\begin{abstract}
D- STATCOM is a FACTS device that is utilized in the DS for regulating the power utility. The D-STATCOM is good in good in solving the power quality problems, when placed at an optimal location. In this research work, a hybridization model is utilized for optimal placement and sizing of D-STATCOM in the distribution system. The hybridization model referred as JCF-LA is utilized in this research work and it is the conceptual hybridization of JA and LA, respectively. The optimal placement as well as sizing of D-STATCTOM is accomplished by meeting the objectives like "Demand meet, Voltage Stability Index (VSI), Cost of Energy loss (CEL), Cost of DSATCOM and Voltage Stability Margin (VSM)". Finally, a performance based evaluation is accomplished with JCF-LA based optimal placement and sizing model over the other optimization models. Here, the D-STATCOM cost of the proposed work with JCF-LA is 320(\$), while the DSTATCOM cost of the proposed work with ABC, JA, LA, PSO and GWO is 376.54(\$), 376.49(\$), 376.41(\$), 376.55(\$) and 376.26(\$), respectively.
\end{abstract}

Keywords: D-STATCOM; Voltage Stability Margin; JCF- LA; Demand meet; Cost.

\begin{tabular}{ll} 
Nomenclature & \\
\hline Abbreviation & Description \\
\hline CEL & Cost of Energy loss \\
DFACTS & Distribution network Flexible AC Transmission \\
DN & Distribution Networks \\
DS & Distribution System \\
D-STATCOM & Distribution STATic COMpensator \\
ELC & Energy Loss Cost \\
GA & Genetic Algorithm \\
GSA & Gravitational Search Algorithm \\
JA & Jaya Algorithm \\
LA & Lion Algorithm \\
SSSC & Synchronous Series Compensator \\
TNP & Total Net Profit \\
UPQC & Unified Power Flow Conditioner \\
VSC & Voltage Source Converter \\
VSM & Voltage Stability Margin \\
\hline
\end{tabular}

\section{Introduction}

In developing countries like India, the electrical energy demand is rising in a faster way [6-11]. From the "total generated power", $13 \%$ is wasted in the distribution side as a loss. From the consumer point of view, the the overall efficiency of power system can be improved by reducing the losses. The DFACTS is highly advanced equipment that has the potential of reducing the losses in the distribution system [1215]. The DSTATCOM, UPQC, and Static SSSC are the DFACTS devices. Among these devices, the DSTATCOM is embedded with the significant characters like harmonic production minimization, low power minimization, low cost, high regulatory capability as well. The "DSTATCOM is a shunt connected VSC" that is applied in the DN for providing reactive power control, power factor and for compensating 
the bus voltage. Further, when specific load is applied to the distribution system, correct amount of "leading or lagging compensating current" is injected by DSTATCOM in order to meet the total demand.

In the radial DS, the optimum allocation of DSTATCOM is significant in maximising the stability, power quality, and minimization of the power loss. In radial DS, a considerable impact is being provided in order to compute the optimal location and sizing of DSTATCOM [6]. Inappropriate placement of the DSTATCOM tends to diminish the power quality and even endanger the operations of the entire system. Moreover, the current quality of the utility in distribution system is improved by using distribution static compensator (DSTATCOM). The voltage source inverter (VSI) of DSTATCOM is connected to utility through an interfacing inductor for smoothing the current. But the required inductance value is high in conventional DSTATCOM. Due to this, the requirement of DC-link voltage of VSI is increased to improve the current quality. Only less count of researches has been focussed on DSTATCOM allocation. The optimization algorithms are playing a mightier role in placing the DSTATCOM optimally in the distribution network.

The major contribution of this research work is depicted below:

$\checkmark$ The optimal placement and sizing of D-STATCOM with a hybridized optimization algorithm referred as JCF-LA is the amalgamation of JA and LA, respectively.

$\checkmark$ The objective of optimal placement is achieved by means of considering the like "Demand meet, VSI, CEL, Cost of DSATCOM and VSM".

\section{Literature Review}

\subsection{Related Works}

In 2018, Gupta et al. [1] have proposed a novel approach for optimal placement of D-STATCOM in "mesh distribution systems". The major objective of this research work was to (a) optimally place the DSTATCOM on the basis of the new voltage sensitivity index, (b) optimal sizing of the D-STATCOM with load growth scenario for seasonal loads, (c) D-STATCOM size determination and placement comparison over the existing sensitivity methods and (d) optimal D-STATCOM impact on enhancement of "voltage stability margin, cost of energy savings and reduction in the energy loss".

In 2017, Rao and Rao [2] have determined the STATCOM optimal parameters and optimum location determination in the power system. the major objective of this research work is the minimization of the system power loss. a "two-stage approach" was proposed STATCOM optimal placement. The generalized approach was utilized for STATCOM localization in the optimal manner on the basis of the sensitivity analysis. The "Newton- Raphson (N-R) power flow technique" was utilized for setting the parameters of the STATCOM. The 14-bus test system wwas utilized for testing the proposed approach in terms of improved in voltage profile and power loss minimization.

In 2017, Mohammadi et al. [3] have utilized the fuzzy membership function corresponding to the loss sensitivity for weak nodes selection during the placement of DSTATCOM in the power system. The GA governs the DFACTS tie switches selection and parameter settings optimally. They have tested the proposed model in the "IEEE 33-bus and IEEE 69-bus test systems" and the outcomes have shown the efficiency of the proposed work in terms of power loss minimization.

In 2019, Arya et al. [4] have utilized the GSA for accurate evaluation of the DS by placing the DSTATCOM optimally. The major objective behind this research work was to "minimize the power loss, voltage profile index and for improving the annual energy saving and voltage profile" for DN operator. The proposed model was tested on "IEEE 33 and IEEE 69 bus systems".

In 2017, Sanam et al. [5] have presented an optimization of ELC for optimal sizing of the DSTATCOM in DN. The major objective behind this research was to maximize the TNP/cost savings. They have solved the objective function in terms of "optimal reactive power compensation". The DSTATCOM optimal placement and sizing long with the optimal reactive power compensation were achieved by voltage profile improvement and TNP maximization, and network power loss and total ELC reduction.

\section{D-STATCOM Design in DSAND Considered Sensitivity Indices}

\subsection{Proposed Procedure}

The optimal placement of D-STACOM is based on the following steps: 
Step 1: Place D-STATCOM on the basis of the sensitivity indices (FVSI, VSI, VESI, CPLS and PSI) at the bus

Step 2: Find the bus with lower sensitivity and select it as the optimal bus for D-STATCOM placement. Step 3: The optimal bus is selected with the JCF-LA algorithm on the basis of multiple objectives like "Demand meets, VSI, CEL, Cost of DSATCOM and VSM".

The major objective behind the current research work is mathematically expressed in Eq. (1).

$$
\mathrm{OB}=\min \left(\begin{array}{l}
\text { Demand meet, VSIMeet } \\
\text { CEL, Cost of DSTATCOM, VSM }
\end{array}\right)
$$

In this research work, the IEEE-33 bus system is taken into consideration; its location $\mathrm{LO}_{1, \ldots, 33}$ and its position in 24 hours $\mathrm{P}_{0, \ldots, 24}$ are fed as input to the JCF-LA algorithm.

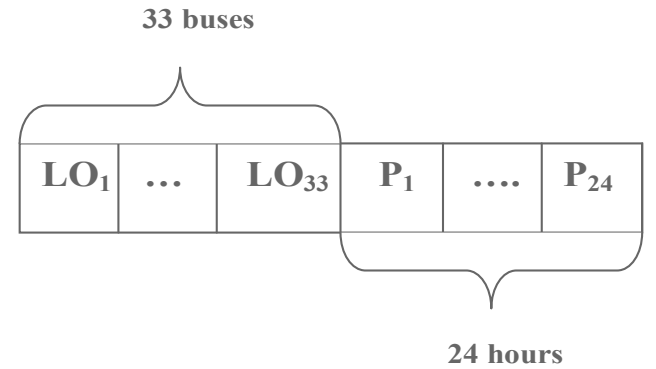

Fig. 1. Solution Encoding

Step 4: at the selected bus, place D-STATCOM, and reactive power demand is varied upto maximum and the corresponding total power losses is recorded.

Step 5: On the basis of the minimum total loss, optimal D-STATCOM location is identified.

\subsection{D-STATCOM Design}

The static model of the D-STATCOM is utilized for "distribution system load flow analysis". At the connected bus, the reactive power is supported by the device and this in turn aids the enhancement of the voltage profile and reduction in the losses. Therefore, the D-STATCOM also influences the voltages of adjacent buses. In the proposed D-STATCOM model, two new voltages, $\mathrm{Vol}_{\mathrm{n}}^{\prime}$ and $\mathrm{Vol}_{\mathrm{m}}$ are considered. Here, $\mathrm{Vol}_{\mathrm{n}}^{\prime}$ is introduced at the candidate bus and $\mathrm{Vol}_{\mathrm{m}}{ }$ is introduced at the preceding bus. The current $I_{m}^{\prime}=I_{\hat{m}}+I_{D S}$, where $I_{D S}$ is the current injected by D-STATCOM and it is said to be in quadrature with the voltage. Therefore, after the installation of D-STATCOM the new voltage acquired is denoted as per Eq. (1).

$$
\begin{aligned}
\operatorname{Vol}_{\mathrm{n}} \angle \theta_{\mathrm{n}}^{\prime} & =\operatorname{Vol}_{\mathrm{m}}^{\prime} \angle \theta_{\hat{\mathrm{m}}}^{\prime}-\left(\operatorname{Re}_{\hat{\mathrm{m}}}+\mathrm{jL}_{\hat{\mathrm{m}}}\right)\left(\mathrm{I}_{\hat{\mathrm{m}}} \angle \delta\right) \\
& -\left(\operatorname{Re}_{\hat{\mathrm{m}}}+\mathrm{j} \mathrm{L}_{\hat{\mathrm{m}}}\right)\left(\mathrm{I}_{\mathrm{DS}} \angle\left(\frac{\pi}{2}+\theta_{\mathrm{n}}^{\prime}\right)\right)
\end{aligned}
$$

In Eq. (1), the real and imaginary part is split, and hence the expression becomes as $T=\frac{-G \pm \sqrt{\mathrm{P}}}{2 \mathrm{H}}$, which is the desired root of Eq. (1). Therefore, the D-STATCOM reactive power is expressed as per Eq. (2) and current incorporated to the system through D-STATCOM is expressed as per Eq. (3), respectively.

$$
\begin{aligned}
& \angle \mathrm{I}_{\mathrm{DS}}=\frac{\pi}{2}+\theta_{\mathrm{m}}^{\prime}=\frac{\pi}{2}+\sin ^{-1} \mathrm{~T} \\
& \mathrm{II} \mathrm{I}_{\mathrm{DS}} \mathrm{I}=\frac{\mathrm{Vol}_{\mathrm{m}} \cos \theta_{\mathrm{m}}^{\prime}-\mathrm{a}_{1}}{-\mathrm{a}_{4} \sin \theta_{\mathrm{m}}^{\prime}-\mathrm{a}_{3} \cos \theta_{\mathrm{m}}^{\prime}} \\
& \mathrm{jQ}_{\mathrm{DS}}=\left(\mathrm{Vol}_{\mathrm{m}}^{\prime} \angle \theta_{\mathrm{m}}^{\prime}\right) \cdot\left(\mathrm{I}_{\mathrm{DS}} \angle\left(\frac{\pi}{2}+\theta_{\mathrm{m}}^{\prime}\right)\right)^{*}
\end{aligned}
$$

Here,

$$
\begin{aligned}
& \mathrm{T}=\sin \theta_{\mathrm{m}}^{\prime} \\
& \mathrm{H}=\left(\mathrm{a}_{1} \mathrm{a}_{3}-\mathrm{a}_{2} \mathrm{a}_{4}\right)^{2}+\left(\mathrm{a}_{1} \mathrm{a}_{4}+\mathrm{a}_{2} \mathrm{a}_{3}\right)^{2} \\
& \mathrm{G}=2\left(\mathrm{a}_{1} \mathrm{a}_{3}-\mathrm{a}_{2} \mathrm{a}_{4}\right) \cdot\left(V^{\prime} l_{\mathrm{m}}\right)\left(\mathrm{a}_{4}\right)
\end{aligned}
$$




$$
\begin{aligned}
\mathrm{P} & =\left(\mathrm{Vol}_{\mathrm{m}}^{\prime} \cdot \operatorname{Re}_{\hat{\mathrm{m}}}\right)^{2}-\left(\mathrm{a}_{1} \mathrm{a}_{4}+\mathrm{a}_{2} \mathrm{a}_{3}\right)^{2} \\
\mathrm{P} & =\mathrm{G}^{2}-4 \mathrm{HP} \\
\mathrm{a}_{1} & =-\operatorname{real}\left(\mathrm{Z}_{\hat{\mathrm{m}}} \cdot \mathrm{I}_{\hat{\mathrm{m}}} \angle \delta\right)+\operatorname{real}\left(\mathrm{Vol}_{\mathrm{m}} \angle \theta_{\hat{\mathrm{m}}}^{\prime}\right) \\
\mathrm{a}_{2} & =-\operatorname{imag}\left(\mathrm{Z}_{\hat{\mathrm{m}}} \cdot \mathrm{I}_{\hat{\mathrm{m}}} \angle \delta\right)+\operatorname{imag}\left(\mathrm{Vol}_{\mathrm{m}} \angle \theta_{\hat{\mathrm{m}}}^{\prime}\right) \\
\mathrm{a}_{3} & =-\mathrm{X}_{\hat{\mathrm{m}}} \\
\mathrm{a}_{4} & =-\mathrm{Re}_{\hat{\mathrm{m}}}
\end{aligned}
$$

Now, $\mathrm{T}$ has two roots and the appropriate value of the roots can be found by means of determining the boundary factors.

$$
\mathrm{Vol}_{\mathrm{m}}=\mathrm{Vol}_{\mathrm{m}} \Rightarrow \mathrm{I}_{\mathrm{DS}}=0 \& \theta_{\mathrm{m}}^{\prime}=\theta_{\mathrm{m}}
$$

Then, for D-STATCOM optimal location and placement in mesh DS, the sensitivity indices like "Combined Power Loss Sensitivity (CPLS), Voltage Sensitivity Index (VSEI), Proposed Stability Index (PSI), Fast Voltage Stability Index (FVSI) and Voltage Stability Index (VSI)" are taken into consideration.

\subsection{Sensitivity Index}

FVSI is shown mathematically in Eq. (15)

$$
\mathrm{FVSI}=\frac{4 \mathrm{Q}_{\mathrm{j}} \mathrm{Z}_{\mathrm{ij}}^{2}}{\mathrm{X}_{\mathrm{ij}} \operatorname{Vol}_{\mathrm{i}}^{2}}
$$

In which, the magnitude of the line impedance $Z$, line reactance $X$, receiving end reactive power $Q_{j}$ and voltage at the transmitting end $V_{i}$ are the crucial parameters. The high FVSI value bus is extremely sensitive to instability and hence these bus are selected as an appropriate bus for D-STATCOM placement.

The mathematical formula for VSEI is shown in Eq. (16).

$$
\mathrm{VSEI}=\frac{4 \mathrm{~L}}{\mathrm{~V}_{1}^{2}}\left(\mathrm{Q}_{2}+\frac{\mathrm{P}_{2}^{2}}{\mathrm{Q}_{2}}\right) \leq 1
$$

The bus with greatest VSEI value is selected for optimal design of D-STATCOM as it is highly vulnerable to stability.

VSI is shown mathematically in Eq. (17)

$$
\mathrm{VSI}=\frac{[1-\cos 2 \phi]}{2 \mathrm{Vol}_{1}^{2} \sin ^{2}\left(-\delta_{2}+\delta_{1}-\phi\right)}+4\left[\frac{\mathrm{Q}_{2} \hat{\mathrm{Re}}}{\mathrm{L}}+\mathrm{Q}_{2} \mathrm{~L}\right]
$$

The bus with peak VSI value is selected as the appropriate bus for location of D-STATCOM.

The mathematical formula for CPLS is shown in Eq. (18) - Eq. (22).

$$
\begin{aligned}
& \frac{\partial \mathrm{P}^{\text {loss }}}{\partial \mathbf{Q}_{2}}=\frac{2 * \mathbf{Q}_{2 * \mathrm{G} \mid \mathrm{j} \mathrm{l}}}{\mathrm{Vol}_{2}^{2}} \\
& \frac{\partial \mathbf{Q}^{\text {loss }}}{\partial \mathbf{Q}_{2}}=\frac{2 * \mathbf{Q}_{2 * \mathrm{~L} \mid \mathrm{j}}}{\mathrm{Vol}_{2}^{\prime 2}}
\end{aligned}
$$

The CPLS with respect to reactive power $\mathrm{Q}_{\mathrm{CPLS}}$ is shown in Eq. (20).

CPLS with respect to terms of real power $\mathrm{P}_{\text {CPLS }}$

$$
\mathrm{Q}_{\mathrm{CPLS}}=\frac{\partial \mathrm{S}^{\text {loss }}}{\partial \mathbf{Q}_{2}}=\mathrm{j} \frac{\partial \mathbf{Q}^{\text {loss }}}{\partial \mathbf{Q}_{2}}+\frac{\partial \mathrm{P}^{\text {loss }}}{\partial \mathbf{Q}_{2}}
$$

$$
\mathrm{P}_{\mathrm{CPLS}}=\frac{\partial \mathrm{S}^{\text {loss }}}{\partial \mathrm{P}_{2}}=\mathrm{j} \frac{\partial \mathrm{Q}^{\text {loss }}}{\partial \mathrm{P}_{2}}+\frac{\partial \mathrm{P}^{\text {loss }}}{\partial \mathrm{P}_{2}}
$$

The Loss sensitivity matrix (LSI) is acquired with the aid of the power flow analysis and it is expressed as per Eq. (22).

$$
=\left|\begin{array}{cc}
\frac{\partial \mathrm{P}^{\text {loss }}}{\partial \mathrm{P}_{2}} & \frac{\partial \mathbf{Q}^{\text {loss }}}{\partial \mathrm{P}_{2}} \\
\frac{\partial \mathrm{P}^{\text {loss }}}{\partial \mathbf{Q}_{2}} & \frac{\partial \mathbf{Q}^{\text {loss }}}{\partial \mathbf{Q}_{2}}
\end{array}\right|
$$

In D-STATCOM modelling, the bus with highest CPLS is selected as the optimal bus. 
The stability index' arithmetical design is described as follows and as per Eq. (23), the modelling of the branch current takes place.

$$
I_{i j}=\left[\frac{P_{j}+j Q_{j}}{V_{j o l} \angle \delta}\right]
$$

At the receiving end, the bus voltage is formulated as shown below:

$$
\mathrm{Vol}_{\mathrm{j}} \angle \delta=\mathrm{V}_{\mathrm{i}} \angle 0-(\operatorname{Re}+\mathrm{jX}) \mathrm{I}_{\mathrm{ij}}
$$

Replace Eq. (15) in Eq. (16).

$$
\begin{aligned}
& \mathrm{Vol}_{\mathrm{j}} \angle \delta=\operatorname{Vol}_{\mathrm{i}} \angle 0-(\operatorname{Re}+\mathrm{jX})\left[\frac{\mathrm{P}_{\mathrm{j}}+\mathrm{jQ}_{\mathrm{j}}}{\operatorname{Vol}_{\mathrm{j}} \angle-\delta}\right] \\
& \mathrm{Vol}_{\mathrm{j}}^{2}=\operatorname{Vol}_{\mathrm{i}} \mathrm{Vol}_{\mathrm{j}} \angle-\delta-(\mathrm{Re}+\mathrm{jX})\left(\mathrm{P}_{\mathrm{j}}-\mathrm{jQ}_{\mathrm{j}}\right) \\
& \mathrm{Vol}_{\mathrm{j}} \angle \delta=\operatorname{Vol}_{\mathrm{i}} \angle 0-(\operatorname{Re}+\mathrm{jX})\left[\frac{\mathrm{P}_{\mathrm{j}}+\mathrm{jQ}_{\mathrm{j}}}{\mathrm{Vol}_{\mathrm{j}} \angle \delta}\right] \\
& \mathrm{Vol}_{\mathrm{j}}^{2}=\mathrm{Vol}_{\mathrm{i}} \mathrm{Vol}_{\mathrm{j}} \cos \delta- \\
& -\mathrm{jVol}_{\mathrm{i}} \mathrm{Vol}_{\mathrm{j}} \sin \delta-(\mathrm{Re}+\mathrm{jX})\left(\mathrm{P}_{\mathrm{j}}-\mathrm{jQ} \mathrm{Q}_{\mathrm{j}}\right) \\
& \mathrm{Vol}_{\mathrm{j}}^{2}+\left[\mathrm{P}_{\mathrm{j}} \operatorname{Re}+\mathrm{Q}_{\mathrm{j}} \mathrm{X}+\mathrm{j}\left(\mathrm{P}_{\mathrm{j}} \mathrm{X}-\mathrm{Q}_{\mathrm{j}} \mathrm{Re}\right)\right]= \\
& \mathrm{Vol}_{\mathrm{i}} \mathrm{Vol}_{\mathrm{j}} \cos \delta-\mathrm{j}_{\mathrm{Vol}} \mathrm{Vol}_{\mathrm{j}} \sin \delta
\end{aligned}
$$

As per Eq. (22), split the real and imaginary parts.

Consider $\delta \approx 0$

$$
\begin{aligned}
& \mathrm{Vol}_{j}^{2}+\mathrm{P}_{\mathrm{j}} \mathrm{Re}+\mathrm{Q}_{\mathrm{j}} \mathrm{X}=\mathrm{Vol}_{\mathrm{i}} \mathrm{Vol}_{\mathrm{j}} \cos \delta \\
& \mathrm{P}_{\mathrm{j}} \mathrm{X}-\mathrm{Q}_{\mathrm{j}} \mathrm{Re}=-\mathrm{Vol}_{\mathrm{i}} \mathrm{Vol}_{\mathrm{j}} \sin \delta
\end{aligned}
$$

$$
\begin{aligned}
& \mathrm{P}_{\mathrm{j}} \operatorname{Re}+\mathrm{Vol}_{\mathrm{j}}^{2}+\mathrm{Q}_{\mathrm{j}} \mathrm{X}=\mathrm{Vol}_{\mathrm{i}} \mathrm{Vol}_{\mathrm{j}} \\
& -\mathrm{Q}_{\mathrm{j}} \operatorname{Re}+\mathrm{P}_{\mathrm{j}} \mathrm{X}=0 \\
& \mathrm{X}=\frac{\operatorname{Re} \cdot \mathrm{Q}_{\mathrm{j}}}{\mathrm{P}_{\mathrm{j}}}
\end{aligned}
$$

Replace Eq. (26) in Eq. (22)

$$
\begin{aligned}
& P_{j} R e+Q_{j} \frac{Q_{j} R e}{P_{j}}+\operatorname{Vol}_{j}^{2}=\operatorname{Vol}_{i} \operatorname{Vol}_{j} \\
& \left(\frac{Q_{j}^{2}}{P_{j}}+P_{j}\right) R e+\operatorname{Vol}_{j}^{2}-\operatorname{Vol}_{j} \operatorname{Vol}_{i}=0
\end{aligned}
$$

In this research work the stable bus voltage is achieved by introducing a novel stability index. This is expressed in Eq. (37) - Eq. (39).

$$
\begin{aligned}
& \operatorname{Vol}_{\mathrm{i}}^{2}-4\left(\mathrm{P}_{\mathrm{j}}+\frac{\mathrm{Q}_{\mathrm{j}}^{2}}{\mathrm{P}_{\mathrm{j}}}\right) \operatorname{Re} \geq 0 \\
& 1 \geq \frac{4 \operatorname{Re}}{\operatorname{Vol}_{\mathrm{i}}^{2}}\left(\mathrm{P}_{\mathrm{j}}+\frac{\mathrm{Q}_{\mathrm{j}}^{2}}{\mathrm{P}_{\mathrm{j}}}\right) \\
& \mathrm{PSI}=\frac{4 \operatorname{Re}}{\operatorname{Vol}_{\mathrm{i}}^{2}}\left(\mathrm{P}_{\mathrm{j}}+\frac{\mathrm{Q}_{\mathrm{j}}^{2}}{\mathrm{~V}_{\mathrm{i}}^{2}}\right) \leq 1
\end{aligned}
$$

When PSI $<1$, the system is working under usual operating conditions, PSIcloseto 0 , then the system is stable and if PSI $>>1$, the system is susceptible to instability. Therefore, for optimal placement, the bus with lower PSI is selected.

In addition to this, the "load, load growth, cost of energy loss and D-STATCOM cost" are considered for optimal placement of D-STATCOM in mesh DS

\subsection{Modelling of Cost Of Energy Loss, Load, D -STATCOM Cost,Load Growth}

CEL: the mathematical formula of CEL is expressed in Eq. (40), in which $\mathrm{P}^{\mathrm{T}(\mathrm{Loss})}$ is the total power loss, $\mathrm{E}_{\mathrm{c}}^{\text {rates }}$ is the energy rate and $\mathrm{T}$ symbolizes time in (hours). 


$$
\mathrm{CEL}=\mathrm{P}^{\mathrm{T}(\mathrm{Loss})} *\left(\mathrm{E}_{\mathrm{c}}^{\text {rates }} * \mathrm{~T}\right) \$
$$

In this research work, $\mathrm{E}_{\mathrm{c}}^{\text {rates }}$ is fixed as $0.06 \$ / \mathrm{kW} \mathrm{h}$ and $\mathrm{T}$ is $8760 \mathrm{~h}$.

Cost of D-STATCOM C $\mathrm{C}^{\text {D- STATCOM }}$ : Eq. (41) Shows the mathematical formula for the reactive power cost in D-STATCOM. Here, $\mathrm{C}^{\mathrm{INV} . \mathrm{D}-\mathrm{STSTCOM}}$ is the investment cost and it is set as $50 \$ / \mathrm{kVAl}$. The asset rate of return is symbolized as Rate and longevity of D-STATCOM (years) is represented as mDST and it is set as 30 in this research work.

$$
\mathrm{C}^{\mathrm{D}-\mathrm{STATCOM}}=\mathrm{C}^{\mathrm{INV} . \mathrm{D}-\mathrm{STSTCOM}} \times \frac{[1+\text { Rate }]^{\mathrm{mDST}} * \text { Rate }}{[1+\text { Rate }]^{\mathrm{mDST}}-1}
$$

Load growth : The mathematical formula for load growth is shown in Eq. (42), in which $\mathrm{L}$ is the load and the annual growth rate is denoted as a.In addition, the plan period is symbolized as period .

$$
\mathrm{L}=\mathrm{L} \times(1+\mathrm{a})^{\text {period }}
$$

In this research work, period is set as 5 and a is set as $10 \%$.

Load model: The practical load model is mathematically expressed in Eq. (43) and Eq. (44) respectively. Here, $P_{0}$ and $Q_{0}$ is the real power and reactive power that is fed as input to reference voltage $\mathrm{Vol}_{0}$.in addition, $\alpha, \beta$ and $\gamma$ are the residential load percentage, commercial load percentage and industrial load percentage, respectively.

$$
\begin{aligned}
& \mathrm{P}=\mathrm{P}_{\mathrm{o}}\left[\alpha\left(\frac{\mathrm{Vol}}{\mathrm{Vol}_{\mathrm{o}}}\right)^{\mathrm{m}_{\mathrm{al}}}+\beta\left(\frac{\mathrm{Vol}}{\mathrm{Vol}_{\mathrm{o}}}\right)^{\mathrm{m}_{\mathrm{ac}}}+\gamma\left(\frac{\mathrm{Vol}}{\mathrm{Vol}_{\mathrm{o}}}\right)^{\mathrm{m}_{\mathrm{ai}}}\right] \\
& \mathrm{Q}=\mathrm{Q}_{\mathrm{o}}\left[\alpha\left(\frac{\mathrm{Vol}}{\mathrm{Vol}_{\mathrm{o}}}\right)^{\mathrm{m}_{\mathrm{bl}}}+\beta\left(\frac{\mathrm{Vol}}{\mathrm{Vol}_{\mathrm{o}}}\right)^{\mathrm{m}_{\mathrm{bc}}}+\gamma\left(\frac{\mathrm{Vol}}{\mathrm{Vol}_{\mathrm{o}}}\right)^{\mathrm{m}_{\mathrm{bi}}}\right]
\end{aligned}
$$

Voltage Stability Margin (VSM): The mathematical expression for VSM is shown in Eq. (45). Here, $\mathrm{Q}^{\text {load }}$ is the total reactive power loads and $\mathrm{P}^{\text {load }}$ is the total real power loads at the entire nodes.

$$
\begin{aligned}
\mathrm{VSM}= & \operatorname{Vol}(\mathrm{se}))^{4}-\left(\mathrm{P}^{\text {load }}(\text { rate }) \mathrm{X}-\mathrm{Q}^{\text {load }}(\text { rate }) \mathrm{X}\right)^{2}- \\
& 4|\mathrm{~V}(\mathrm{se})|^{4}\left(\mathrm{P}^{\text {load }}(\text { rate }) \mathrm{X}-\mathrm{Q}^{\text {load }}(\text { rate }) \mathrm{X}\right)
\end{aligned}
$$

Let's consider a data format (DF matrix) in which " $R$ ate $=\mathrm{DF}(\mathrm{i}, \mathrm{j} 1)$, $\mathrm{se}=\mathrm{DF}(\mathrm{i}, \mathrm{j}), \mathrm{R}=\mathrm{DF}(\mathrm{i}, \mathrm{j} 2)$ and $\mathrm{X}=\mathrm{DF}(\mathrm{i}, \mathrm{j} 3)$ ". The counter is denoted by the symbol $\mathrm{i}$ and the sending bus number of line is denoted as $\mathrm{j}$ and the receiving bus number of line $\mathrm{j} 1$. In addition, $\mathrm{j} 2$ and $\mathrm{j} 3$ provides the resistance and reactance of branch.

\subsection{JCF-LA Model}

The JCF-LA [17] model is the conceptual amalgamation of LA and JA. The LA is a renowned algorithm that is good in solving the complex optimization problems. But, it suffers from minimal convergence rate. On the other hand, the JA has maximal convergence with minimal accuracy. Moreover, the ability to deal with problems using hybrid algorithms exhibits local minima and offers quick convergence to the optimal solution. Therefore, JA and LA were blend together to form JCF-LA. The steps followed in the JCF-LA are depicted below:

Step 1: Population initialization, in which the search agents of both LA and JA are initialized.

Step 3: Evaluate the fitness of the male lion $\mathrm{fe}\left(\mathrm{X}^{\mathrm{mal}}\right)$, female lion $\mathrm{fe}\left(\mathrm{X}^{\mathrm{fema}}\right)$ and nomadic lion fe $\left(\mathrm{X}_{1}^{\mathrm{nom}}\right)$ of LA.

Step 4: Set the reference fitness fe ${ }^{\text {refe }}$ asfe $\left(\mathrm{X}^{\mathrm{mal}}\right)$ and $\mathrm{N}_{\mathrm{h}}$ specifies the generation counts, which are set as $\mathrm{N}_{\mathrm{h}}=0$.

Step 5: Perform fertility assessment using Eq. (46) - Eq. (48)

$$
\mathrm{x}_{\mathrm{v}}^{\text {fema+ }}= \begin{cases}\mathrm{x}_{\mathrm{k}}^{\text {fema+ }} ; & \text { if } \mathrm{v}=\mathrm{k} \\ \mathrm{x}_{\mathrm{ve}}^{\text {fmae }} ; & \text { otherwise }\end{cases}
$$

In which $\mathrm{x}_{\mathrm{v}}^{\text {femat }}$ and $\mathrm{x}_{\mathrm{k}}^{\text {femat }}$ are $\mathrm{X}^{\text {femat }}$, $\mathrm{s} \mathrm{v}^{\text {th }}$ and $\mathrm{k}^{\text {th }}$ vector element.

$$
\mathrm{x}_{\mathrm{k}}^{\mathrm{fema+}}=\min \left[\mathrm{x}_{\mathrm{k}}^{\mathrm{MAX}}, \max \left(\mathrm{x}_{\mathrm{k}}^{\mathrm{MIN}}, \nabla_{\mathrm{k}}\right)\right]
$$

Here, the female update is denoted as $\nabla$

$$
\nabla_{\mathrm{k}}=\left[\mathrm{x}_{\mathrm{k}}^{\text {fema }}+\left(0.1 \mathrm{ran}_{2}-0.05\right)\left(\mathrm{x}_{\mathrm{k}}^{\mathrm{mal}}-\operatorname{ran}_{2} \mathrm{x}_{\mathrm{k}}^{\text {fema }}\right)\right]
$$

Here $\operatorname{ran}_{1}$ and $\operatorname{ran}_{2}$ are the arbitrary integers that resides within the limit 0,1. 
Step 6: In the mating process of LA, the cubpool is generated with JA based LA instead of the existing LA algorithm. The update expression of JA based LA is expressed in Eq. (49).

$$
\mathrm{X}_{\mathrm{j}, \mathrm{i}, \mathrm{i}}^{\prime}=\mathrm{X}_{\mathrm{j}, \mathrm{p}, \mathrm{i}}+\mathrm{ra}_{1 \mathrm{j}, \mathrm{i}}\left(\mathrm{X}^{\mathrm{mal}}-\left|\mathrm{X}_{\mathrm{j}, \mathrm{p}, \mathrm{i}}\right|\right)-\mathrm{ra}_{2 \mathrm{j}, \mathrm{i}}\left(\mathrm{X}^{\text {fema }}-\left|\mathrm{X}_{\mathrm{j}, \mathrm{i}, \mathrm{i}}\right|\right)
$$

In which, $X_{j, p, i}$ is the $i^{\text {th }}$ iteration corresponding to the $p^{\text {th }}$ candidate with $j^{\text {th }}$ variable. the random numbers $\mathrm{ra}_{1 \mathrm{j}, \mathrm{i}}$ and $\mathrm{ra}_{2 \mathrm{j}, \mathrm{i}}$ are expressed as $\mathrm{ra}_{1 \mathrm{j}, \mathrm{i}}\left(\mathrm{X}_{\mathrm{j}, \mathrm{best}, \mathrm{i}}-\left|\mathrm{X}_{\mathrm{j}, \mathrm{p}, \mathrm{i}}\right|\right)$ and $\mathrm{ra}_{2 \mathrm{j}, \mathrm{i}}\left(\mathrm{X}_{\mathrm{j}, \mathrm{worst}, \mathrm{i}}-\left|\mathrm{X}_{\mathrm{j}, \mathrm{p}, \mathrm{i}}\right|\right)$, respectively. Here, $X_{j, \text { best }, \mathrm{i}}$ and $X_{j, \text { worst }, \mathrm{i}}$ is best and worst candidates of $j^{\text {th }}$ variable.

Step 7: $\mathrm{X}^{\mathrm{mal}_{\text {cub }}}$ and $\mathrm{X}^{\mathrm{fema}{ }_{-} \mathrm{cub}}$ are acquired by performing the gender clustering

Step 8: The age of the cubs $\mathrm{AE}_{\text {cub }}$ as zero

Step 9: cub growth function is performed

Step 10: territorial defense is followed.

Step 11: If, $\mathrm{AE}_{\text {cub }}<\mathrm{AE}^{\mathrm{MAX}}$, go to Step 9

Step 12: $\mathrm{X}^{\mathrm{mal}}$ and $\mathrm{X}^{\mathrm{fema}}$ are updated by performing the territorial takeover

Step 13: terminate, if the condition among Eq. (50) or Eq. (51) is met

$$
\begin{aligned}
& \mathrm{N}_{\mathrm{h}}>\mathrm{N}_{\mathrm{h}}^{\mathrm{MAX}} \\
& \left|\mathrm{fe}\left(\mathrm{X}^{\text {mal }}\right)-\mathrm{fe}\left(\mathrm{X}^{\text {optimal }}\right)\right| \leq \mathrm{er}_{\mathrm{T}}
\end{aligned}
$$

\section{Results and Discussion}

\subsection{Simulation Procedure}

The proposed optimal placement and location of D-STATCOM with JCF-LA model was implemented in MATLAB and the resultant acquired was noted. The experimentation was performed in "IEEE 33 bus system", in which the count of D-STATCOM is varied from "(i) one D-STATCOM (experiment 1) (ii) two D-STATCOMs (experiment 2) (iii) three D-STATCOM (experiment 3) (iv) four D-STATCOM (experiment 4)." The proposed optimal placement and location of D-STATCOM with JCF-LA model is compared over the proposed optimal placement and location of D-STATCOM with ABC [18], JA [20], LA [19], PSO [21] and GWO [22], respectively in terms of cost analysis and convergence analysis.

\subsection{Analysis Of Proposed Work: With and Without Optimal Placemnet And Sizing of D- STATCOM}

The important of feeding D-STATCOM optimally can be understood clearly from the below analysis. This section tells about the results of IEEE-33 bus system for with and without optimization of D-STATCOM. The results acquired are shown in Table I.

Table 1: Analysis Of D-STATCOM For With And Without Optimization

\begin{tabular}{lll}
\hline Discription & $\begin{array}{l}\text { D-STATCOM with optimal } \\
\text { placement and sizing }\end{array}$ & $\begin{array}{l}\text { D-STATCOM without optimal } \\
\text { placement and sizing }\end{array}$ \\
\hline $\begin{array}{l}\text { Location } \\
\text { Size(kVAr) }\end{array}$ & 30 & - \\
Total reactive power & 1268.5 & 123.3 \\
loss(kVAr) & 108.05 & 250.9 \\
Total active power loss(KW) & 121.37 & 0.88 \\
Minimum voltage(p.u) & 0.906 & - \\
\%loss reduction & 28.5 & \\
\hline
\end{tabular}

Table 2: Cost Analysis of D-STATCOM for IEEE-33 bus system

\begin{tabular}{cllllll}
\hline $\begin{array}{l}\text { Count of D- } \\
\text { STATCOM }\end{array}$ & $\begin{array}{l}\text { ABC based } \\
\text { optimal } \\
\text { placement and } \\
\text { Sizing of D- } \\
\text { STATCOM }\end{array}$ & $\begin{array}{l}\text { JA based } \\
\text { optimal } \\
\text { placement and } \\
\text { Sizing of D- } \\
\text { STATCOM }\end{array}$ & $\begin{array}{l}\text { LA based } \\
\text { optimal } \\
\text { placement and } \\
\text { Sizing of D- } \\
\text { STATCOM }\end{array}$ & $\begin{array}{l}\text { PSO based } \\
\text { optimal } \\
\text { placement and } \\
\text { Sizing of D- } \\
\text { STATCOM }\end{array}$ & $\begin{array}{l}\text { GWO based } \\
\text { optimal } \\
\text { placement and } \\
\text { Sizing of D- } \\
\text { STATCOM }\end{array}$ & $\begin{array}{l}\text { JCF-LA based } \\
\text { optimal } \\
\text { placement and } \\
\text { Sizing of D- } \\
\text { STATCOM }\end{array}$ \\
\hline $\mathbf{1}$ & 376.54 & 376.49 & 376.41 & 376.55 & 376.26 & 320 \\
$\mathbf{2}$ & 557.67 & 557.45 & 555.96 & 564.09 & 554.74 & 530 \\
$\mathbf{3}$ & 745.32 & 748.29 & 745.08 & 743.63 & 738.05 & 700 \\
$\mathbf{4}$ & 917.34 & 935.83 & 934.53 & 935.84 & 921.94 & 910 \\
\hline
\end{tabular}


Table 3: Overall Fitness of the proposed D-STATCOM placement with GOAGA for IEEE-33 bus system

\begin{tabular}{|c|c|c|c|c|c|c|c|c|c|c|c|c|}
\hline \multirow[b]{3}{*}{ Methods } & \multirow{2}{*}{\multicolumn{3}{|c|}{ Multi-objective Fitness }} & \multicolumn{9}{|c|}{ Single objective } \\
\hline & & & & \multicolumn{3}{|c|}{ VSI } & \multicolumn{3}{|c|}{ CEL } & \multicolumn{3}{|c|}{ Loss } \\
\hline & $1^{\text {st }}$ location & $\begin{array}{l}2^{\text {nd }} \\
\text { location }\end{array}$ & $3^{\text {rd }}$ location & $1^{\text {st }}$ location & $\begin{array}{l}2^{\text {nd }} \\
\text { location }\end{array}$ & $\begin{array}{l}3^{\text {rd }} \\
\text { location }\end{array}$ & \begin{tabular}{|l}
$1^{\text {st }}$ \\
location
\end{tabular} & $\begin{array}{l}2^{\text {nd }} \\
\text { location }\end{array}$ & $\begin{array}{l}3^{\text {rd }} \\
\text { location }\end{array}$ & \begin{tabular}{|l|l}
$1^{\text {st }}$ \\
location
\end{tabular} & \begin{tabular}{|l|}
$2^{\text {nd }}$ \\
location
\end{tabular} & $\begin{array}{l}3^{\text {rd }} \\
\text { location }\end{array}$ \\
\hline $\begin{array}{l}\text { ABC based optimal } \\
\text { placement and } \\
\text { Sizing of D- } \\
\text { STATCOM }\end{array}$ & 33.856 & 433.39 & 515.4 & 34.105 & 34.105 & 33.856 & 272.3 & 192.42 & 108.61 & 27.3 & 192.42 & 280 \\
\hline $\begin{array}{l}\text { JA based optimal } \\
\text { placement and } \\
\text { Sizing of D- } \\
\text { STATCOM } \\
\end{array}$ & 34.105 & 272.27 & 420.27 & 33 & 30.753 & 34.105 & 192.42 & 281.41 & 75 & 27.27 & 281.41 & 281.41 \\
\hline $\begin{array}{l}\text { LA based optimal } \\
\text { placement and } \\
\text { Sizing of D- } \\
\text { STATCOM } \\
\end{array}$ & 33.856 & 281.41 & 515.15 & 33.856 & 33.856 & 33.856 & 281.41 & 192.42 & 75.568 & 22.308 & 192.42 & 192.42 \\
\hline $\begin{array}{l}\text { PSO based optimal } \\
\text { placement and } \\
\text { Sizing of D- } \\
\text { STATCOM } \\
\end{array}$ & 30.074 & 272.27 & 420.27 & 30.382 & 34.105 & 30.074 & 192.42 & 281.41 & 75.75 & 21.967 & 281.41 & 281.41 \\
\hline $\begin{array}{l}\text { GWO based optimal } \\
\text { placement and } \\
\text { Sizing of D- } \\
\text { STATCOM } \\
\end{array}$ & 38.381 & 272.27 & 410 & 36.788 & 37.108 & 38.381 & 281.41 & 108.55 & 70 & 22.317 & 108.55 & 108.55 \\
\hline $\begin{array}{l}\text { JCF-LA based } \\
\text { optimal placement } \\
\text { and Sizing of D- } \\
\text { STATCOM }\end{array}$ & 33.856 & 185.88 & 300 & 33 & 21.977 & 26 & 108.55 & 185.88 & 75 & 21.977 & 100.28 & 281.41 \\
\hline
\end{tabular}

\subsection{D-STATCOM Cost Analysis}

The overall achievement of the objective function of the proposed optimal placement and location of DSTATCOM with JCF-LA model and traditional ABC, JA, LA, PSO and GWO are evaluated and the results acquired are shown in Table II. The D-STATCOM cost of the proposed work for optimal placement and sizing with JCF-LA is the lowest one. This evaluation is done by varying the count of DSTATCOM's. Here, when the count of D-STATCOM=2, the lowest cost function is recorded by the proposed work with JCF-LA model. Here, the D-STATCOM cost of the proposed work with JCF-LA is $320(\$)$, while the D-STATCOM cost of the proposed work with ABC, JA, LA, PSO and GWO is 376.54(\$), $376.49(\$), 376.41(\$), 376.55(\$)$ and 376.26(\$), respectively. Thus, from the overall evaluation, it is clear that the proposed optimal placement and location of D-STATCOM with JCF-LA model has achieved the objective of cost minimization

\subsection{Achievemnt of Objective Function}

The objective function of the research work is the minimization of the multiple objectives like "Demand meet, Voltage Stability Index, Cost of Energy loss (CEL), Cost of DSATCOM and Voltage Stability Margin (VSM)". The diverse optimization algorithms are compared for the achievement of both the single and the multiple objectives. The resultant acquired is shown in Table III.

\section{Conclusion}

In this paper, a hybridization model is utilized for optimal placement and sizing of D-STATCOM in the DS. The hybridization model referred as JCF-LA was utilized in this research work and it was the conceptual hybridization of JA and LA, respectively. The optimal placement as well as sizing of DSTATCTOM is accomplished by meeting the objectives like "Demand meet, VSI, CEL, Cost of DSATCOM and VSM". Finally, a performance based evaluation is accomplished with JCF-LA based optimal placement and sizing model over the other optimization models. Thus, the enhancement of the developed model was revealed from the outcomes.

\section{Compliance with Ethical Standards}

Conflicts of interest: Authors declared that they have no conflict of interest.

Human participants: The conducted research follows the ethical standards and the authors ensured that they have not conducted any studies with human participants or animals. 


\section{References}

[1] Atma Ram Gupta,Ashwani Kumar,"Optimal placement of D-STATCOM using sensitivity approaches in mesh distribution system with time variant load models under load growth",Ain Shams Engineering Journal,2018

[2] V. Srinivasa Rao and R. Srinivasa Rao,"Optimal Placement of STATCOM using Two Stage Algorithm for Enhancing Power System Static Security",Energy Procedia,2017

[3] Mohammad Mohammadi,Mahyar Abasi \& A. Mohammadi Rozbahani ,"Fuzzy-GA based algorithm for optimal placement and sizing of distribution static compensator (DSTATCOM) for loss reduction of distribution network considering reconfiguration",Journal of Central South University, Vol.24,pp.245-258,2017

[4] Aadesh Kumar Arya,Ashwani Kumar \& Saurabh Chanana ,"Analysis of Distribution System with D-STATCOM by Gravitational Search Algorithm (GSA)",Journal of The Institution of Engineers (India): Series B, Vol.100,pp.207-215,2019

[5] Joseph Sanam, Sanjib Ganguly, A. K. Panda \& Chaduvula Hemanth ,"Optimization of Energy Loss Cost of Distribution Networks with the Optimal Placement and Sizing of DSTATCOM Using Differential Evolution Algorithm",Arabian Journal for Science and Engineering, Vol.42,pp.2851-2865,2017

[6] A. P. Kumar, G. Siva Kumar and D. Sreenivasarao, "Model predictive control with constant switching frequency for four-leg DSTATCOM using three-dimensional space vector modulation," in IET Generation, Transmission \& Distribution, vol. 14, no. 17, pp. 3571-3581, 492020.

[7] B. Singh, M. Kandpal and I. Hussain, "Control of Grid Tied Smart PV-DSTATCOM System Using an Adaptive Technique," IEEE Transactions on Smart Grid, vol. 9, no. 5, pp. 3986-3993, Sept. 2018. doi: 10.1109/TSG.2016.2645600

[8] R. R. Chilipi, B. Singh and S. S. Murthy, "Performance of a Self-Excited Induction Generator With DSTATCOMDTC Drive-Based Voltage and Frequency Controller," IEEE Transactions on Energy Conversion, vol. 29, no. 3, pp. 545-557, Sept. 2014.

[9] H. Bagheri Tolabi, M. H. Ali and M. Rizwan, "Simultaneous Reconfiguration, Optimal Placement of DSTATCOM, and Photovoltaic Array in a Distribution System Based on Fuzzy-ACO Approach," IEEE Transactions on Sustainable Energy, vol. 6, no. 1, pp. 210-218, Jan. 2015.

[10] B. Singh, P. Jayaprakash and D. P. Kothari, "A T-Connected Transformer and Three-leg VSC Based DSTATCOM for Power Quality Improvement," IEEE Transactions on Power Electronics, vol. 23, no. 6, pp. 27102718, Nov. 2008

[11] S. Hsieh, "Economic Evaluation of the Hybrid Enhancing Scheme With DSTATCOM and Active Power Curtailment for PV Penetration in Taipower Distribution Systems," IEEE Transactions on Industry Applications, vol. 51, no. 3, pp. 1953-1961, May-June 2015.

[12] E. Lei, X. Yin, Z. Zhang and Y. Chen, "An Improved Transformer Winding Tap Injection DSTATCOM Topology for Medium-Voltage Reactive Power Compensation," IEEE Transactions on Power Electronics, vol. 33, no. 3, pp. 2113-2126, March 2018.

[13] B. Singh, P. Jayaprakash, S. Kumar and D. P. Kothari, "Implementation of Neural-Network-Controlled ThreeLeg VSC and a Transformer as Three-Phase Four-Wire DSTATCOM," IEEE Transactions on Industry Applications, vol. 47, no. 4, pp. 1892-1901, July-Aug. 2011.

[14] H. Myneni and G. Siva Kumar, "Simple algorithm for current and voltage control of LCL DSTATCOM for power quality improvement," in IET Generation, Transmission \& Distribution, vol. 13, no. 3, pp. 423-434, 1222019.

[15] N. Patel, N. Gupta and B. C. Babu, "Photovoltaic system operation as DSTATCOM for power quality improvement employing active current control," in IET Generation, Transmission \& Distribution, vol. 14, no. 17, pp. 3518-3529, 492020.

[16] C. Kumar, M. K. Mishra and M. Liserre, "Design of External Inductor for Improving Performance of VoltageControlled DSTATCOM," IEEE Transactions on Industrial Electronics, vol. 63, no. 8, pp. 4674-4682, Aug. 2016.

[17] B. P. Santosh Kumar and K. Venkata Ramanaiah,"Region of interest-based adaptive segmentation for image compression using hybrid Jaya-Lion mathematical approach",International Journal of Computers and Applications ,2019

[18] D.KarabogaB.Basturk, " On the performance of artificial bee colony (ABC) algorithm", Applied Soft Computing, vol. 8, no. 1, pp. 687-697, 2008.

[19] Rajakumar Boothalingam, " Optimization using lion algorithm: a biological inspiration from lion's social behavior", Evolutionary Intelligence, vol.11, no. 1-2, pp.31-52, 2018.

[20] R. Venkata Rao, " Jaya: A simple and new optimization algorithm for solving constrained and unconstrained optimization problems", International Journal of Industrial Engineering Computations, vol. 7, pp. 19-34, 2016.

[21] M.R.Tanweer, S.Suresh, and N.Sundararajan, " Self regulating particle swarm optimization algorithm", Information Sciences, vol. 294, pp. 182-202, 2015.

[22] Seyedali Mirjalili, Seyed Mohammad Mirjalili, Andrew Lewis, "Grey Wolf Optimizer", Advances in Engineering Software, Vol.69, pp, 46-61, 2014. 